\title{
Pengaruh Penambahan Mikropartikel Ekstrak Gambir (Uncaria gambir Roxb) Terhadap Sifat Fisik dan Sensori Sabun Transparan Minyak Kelapa Sawit Microparticle Addition Effect of Gambir Extract on Physical and Sensory Characteristics of Palm Oil Based-Transparent Soap
}

\author{
Neswati*, Sahadi Didi Ismanto dan Vioni Derosya
}

Jurusan Teknologi Industri Pertanian, Fakultas Teknologi Pertanian, Universitas Andalas Kampus Unand Limau Manis Pauh Padang 25163 Sumatera Barat Indonesia

\section{Riwayat Naskah:}

Diterima 022021

Direvisi 092021

Disetujui 10202
ABSTRAK: Penelitian ini bertujuan menentukan tingkat penambahan yang terbaik dari ekstrak gambir (Uncaria gambir, Roxb) dalam bentuk mikropartikel pada sabun transparan berbasis minyak sawit. Penambahan berbagai tingkat mikropartikel ekstrak gambir akan mempengaruhi sifat fisik dan sensori sabun transparan. Berdasarkan hasil pengukuran menggunakan Scanning Electron Microscope (SEM) dengan perbesaran 200x ukuran mikropartikel ekstrak gambir berkisar antara 12,1 - 22,8 $\mu \mathrm{m}$. Penelitian ini menggunakan 8 perlakuan dengan 2 ulangan, yaitu penambahan mikropartikel ekstrak gambir dengan konsentrasi 3\%, 4\%, 5\%,6\%,7\%, 8\%, 9\% dan 10\%. Penambahan 3\% mikropartikel ekstrak gambir memberikan hasil yang terbaik dengan karakteristik kekerasan 17,53 $\pm 1,99$ $\mathrm{kg} / \mathrm{cm} 2$, stabilitas busa $84,18 \pm 0,08 \%$, uji iritasi 0 , nilai warna $4,70 \pm 0,47$ dan transparansi 4,60 $\pm 0,60$.

Kata kunci: ekstrak gambir, iritasi, SEM, stabilitas busa

ABSTRACT: The aim of this study was to gain information related to excellent addition gambir extract microparticle (Uncaria gambir Roxb) for palm oil-based transparent soap. Different addition of gambir extract microparticle affected physical and sensory characteristics of transparent soap. Based on Scanning Electron Microscope (SEM) with 200 times magnification, the size of gambir microparticle were between $12.1-22.8 \mu \mathrm{m}$, There were 8 different concentration (3\%, 4\%, 5\%, 6\%, 7\%, 8\%, 9\%, and 10\%) observed with 2 replications in this study. It showed that the ideal addition of gambir extract was $3 \%$ with $17,53 \pm 1,99 \mathrm{~kg} / \mathrm{cm}^{2}$ for hardness, $84,18 \pm 0,08 \%$ foam stability, zero for irritation test, while sensory analyses were $4,70 \pm 0,47$ for color and $4.60 \pm 0,60$. for transparent. 


\section{Pendahuluan}

Sabun merupakan hasil proses saponifikasi dan proses netralisasi. Proses saponifikasi terjadi dari reaksi trigliserida dengan alkali, sedangkan proses netralisasi terjadi dari reaksi asam lemak bebas dengan alkali. Sabun dapat diklasifikasikan berdasarkan wujudnya berupa sabun padat dan sabun cair. Wujud sabun yang dihasilkan tergantung dari jenis alkali yang digunakan. Sabun juga dapat dibedakan atas sabun opaq (buram), sabun translucent, dan sabun transparan.

Sabun transparan terbuat dari sabun (netralisasi asam lemak) dan pelarut seperti alkohol, gliserin dan gula yang dapat memberikan kejernihan. Sabun transparan lebih menarik dan lebih lembab dibandingkan sabun opaq (Ahmad, Hasan, Muhammad, Bilal, Yusof, dan Idris, 2018). Sabun transparan komersial yang beredar sangat diminati oleh konsumen karena bentuknya yang menarik dan fungsinya tidak hanya untuk membersihkan tetapi juga berfungsi sebagai antibakteri. Bahan aktif antibakteri yang sering dipakai pada sabun transparan komersial adalah tricolasan dan triclocarbon. Food and Drug Administration (2016) menyatakan bahwa penggunaan senyawa antiseptik tricolasan (pada sabun cair) dan triclocarban (pada sabun padat) dalam jangka waktu yang lama dapat membahayakan kesehatan selain itu sifatnya yang tidak mudah terurai dapat membahayakan lingkungan. Kekhawatiran ini dapat dihindari dengan menggunakan bahan aktif antibakteri yang berasal dari tumbuh-tumbuhan, salah satunya gambir.

Gambir merupakan tanaman lokal Sumatera Barat yang mengandung katekin sebagai komponen utamanya. Menurut Sumosa dan Rahayu (2014), ekstrak gambir mengandung katekin yang tidak hanya berfungsi sebagai antioksidan tetapi juga berfungsi sebagai antibakteri yang bersifat antiseptik dan mempunyai aktifitas penyembuh luka. Selain itu katekin gambir juga berfungsi sebagai tabir surya (Setyowati, 2017).

Pada penelitian terdahulu, penambahan ekstrak gambir pada produk perawatan wajah dilakukan oleh Warnida, Lasliyana, dan Sapri (2016) untuk bedak anti jerawat sebanyak 3-9\%. Pada paten yang dimiliki oleh Inomata (1999) dari The Shiseido Research Center, dinyatakan penambahan ekstrak gambir sebanyak $10 \%$ pada anti-aging agent untuk kosmetik. Oleh karena itu, penelitian ini menggunakan 3-10\% penambahan ekstrak gambir.

Khasiat ekstrak gambir dapat dirasakan manfaatnya jika senyawa bioaktifnya mudah terserap kulit. Kemampuan penyerapannya sangat tergantung pada ukuran partikel senyawa bioaktif yang digunakan. Semakin kecil ukuran partikel ekstrak gambir maka semakin mudah diserap kulit sehingga dapat melindungi kulit dari serangan bakteri. Pengecilan ukuran partikel ekstrak gambir menjadi mikropartikel dapat dilakukan dengan menggunakan metode ultrasonikasi.

Pada penelitian Neswati, Ismanto, Derosya (2019) sebelumnya, telah diamati efek penambahan gambir terhadap karakteristik kimia dan sifat antibakteri dari sabun transparan. Namun perlu juga diamati sifat fisik sabun yang dipengaruhi oleh tingkat penambahan terbaik gambir. Penambahan mikropartikel ekstrak gambir dengan konsentrasi yang terlalu banyak akan mengurangi sifat transparan sabun karena ekstrak gambir berwarna coklat. Penambahan mikropartikel ekstrak gambir juga mempengaruhi kekerasan sabun. Banyaknya penambahan ekstrak gambir menyebabkan sabun transparan semakin lunak. Kekerasan sabun akan mempengaruhi masa pakainya. Sifat fisik lainnya yang dapat dipengaruhi oleh tingkat konsentrasi ekstrak gambir pada sabun transparan adalah stabilitas busa, uji iritasi, sifat sensori untuk mengetahui tingkat penerimaan konsumen terhadap warna dan transparansi sabun. Selain itu juga dilakukan pengamatan terhadap morfologi, ukuran serta penyebaran mikropartikel ekstrak gambir dalam sabun transparan yang berpengaruh terhadap penampilan dari sabun.

\section{Bahan dan Metode}

\subsection{Bahan}

Bahan yang diperlukan untuk pembuatan sabun transparan adalah minyak kelapa sawit, $\mathrm{NaOH}$, akuades, etanol 96\%, dan ekstrak gambir yang diperoleh dari Kecamatan Kapur 9 Pangkalan Kabupaten Lima Puluh Kota. Pengecilan ekstrak partikel gambir dengan menggunakan metode ultrasonikasi seperti yang sudah dijelaskan pada Neswati et al. (2019). Sedangkan bahan yang digunakan dalam pengujian ialah alkohol 95\%,

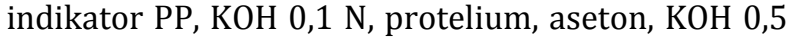
$\mathrm{N}$, kertas cakram, asam stearat, asam sitrat, $\mathrm{NaCl}$, $\mathrm{H}_{2} \mathrm{SO}_{4}$, methyl orange.

\subsection{Alat}

Alat yang digunakan dalam pembuatan sabun diantaranya timbangan analitik, erlenmeyer $250 \mathrm{ml}$, gelas ukur $50 \mathrm{ml}$, gelas piala $250 \mathrm{ml}$, pipet tetes, sendok stainless steel, wadah dari plastik, pemanas, magnetic stirrer, termometer, dan blender. Sedangkan alat yang digunakan untuk uji fisik dan analisis kimia yaitu corong pemisah, pendingin balik, biuret, pendingin tegak, digital force gauge, rotary vacuum evaporator, $\mathrm{pH}$ meter, dan SEM (Scanning Electron Microscopy) merk Hitachi S-3400N dan ultrasonic bath (Merk Elma, S.30H). 
Halaman | 179

\subsection{Rancangan penelitian}

Penelitian ini menggunakan Rancangan Acak Lengkap (RAL) dan dilanjutkan dengan uji DMNRT. Ada delapan level konsentrasi penambahan yaitu $3 \%$, 4\%, 5\%, 6\%, 7\%, 8\%, 9\%, dan 10\% dengan dua ulangan. Perlakuan dalam penelitian ini adalah penambahan ekstrak gambir dalam bentuk mikropartikel pada pembuatan sabun transparan. Penilaian terhadap kesukaan warna dan transparansi juga dilakukan dengan cara mengamati warna dan transparansi sabun oleh panelis.

\subsection{Pelaksanaan penelitian}

\subsubsection{Pembuatan mikropartikel dari ekstrak gambir}

Pembuatan mikropartikel dari ekstrak gambir dilakukan berdasarkan metode Sidqi (2011). Sebanyak 5 gram gambir dilarutkan dalam etanol 96\% sebanyak $100 \mathrm{~mL}$ yang kemudian diekstraksi menggunakan ultrasonifikasi pada suhu $30^{\circ} \mathrm{C}$ selama 60 menit dan diulang kembali selama 60 menit. Ekstrak gambir dipisahkan dari pelarut pada rotary vacuum evaporator selama 40 menit pada suhu $50^{\circ} \mathrm{C}$ dengan tekanan 102 mbar.

\subsubsection{Pembuatan sabun dengan tambahan ekstrak mikropartikel dari gambir}

Pembuatan sabun transparan menggunakan metode Hambali (2005) yang dimulai dengan memanaskan minyak sawit pada $70^{\circ} \mathrm{C}$ sebanyak 30 g. Lima gram asam stearat yang telah dilelehkan, asam sitrat sebanyak $0,3 \mathrm{~g}$ dan $0,2 \mathrm{~g} \quad \mathrm{NaCl}$ ditambahkan ke dalam minyak, kemudian diaduk agar homogen selama \pm 5 menit dengan suhu dijaga pada $70-80^{\circ} \mathrm{C}$. Berikutnya, sebanyak $4,3 \mathrm{~g} \mathrm{NaOH}$ $30 \%$ ditambah dan diaduk hingga trace. Suhu campuran diturunkan hingga $50^{\circ} \mathrm{C}$. Larutan kemudian ditambahkan dan diaduk selama 3 menit dengan $21 \mathrm{~g}$ etanol. Lima gram gula pasir yang telah dilarutkan dalam $5 \mathrm{ml}$ air suling serta 5 g gliserin ditambahkan ke dalam campuran. Ekstrak gambir kemudian ditambahkan sesudah suhu diturunkan menjadi $40^{\circ} \mathrm{C}$. Pengadukan dilanjutkan selama 2 menit agar homogen. Larutan sabun dicetak kemudian ditutup plastik. Analisis dilakukan setelah 24 jam saat sabun mengeras.

\subsection{Pengamatan}

Pada mikropartikel ekstrak gambir dilakukan pengamatan SEM (Aulia, 2013). SEM yang digunakan adalah merk Hitachi S-3400N. Langkah kerja SEM adalah 1) sebuah pistol elektron memproduksi sinar elektron dan dipercepat dengan anoda; 2) lensa magnetic memfokuskan elektron menuju ke sampel; 3) sinar elektron yang terfokus memindai (scan) keseluruhan sampel dengan diarahkan oleh koil pemindai; 4) ketika elektron mengenai sampel maka sampel akan mengeluarkan elektron baru yang akan diterima oleh detektor dan dikirim ke monitor (CRT).

Pengamatan terhadap sabun mikropartikel ekstrak gambir adalah: Kekerasan (Retnowati, Kumoro, Ratnawati, dan Budiyati, 2013) yaitu menggunakan sabun yang berukuran panjang $12 \mathrm{~cm}$, lebar $5 \mathrm{~cm}$ dan tebal $2 \mathrm{~cm}$, dianalisis kekerasannya menggunakan texture analyzer dengan ukuran penetrator $0,6 \mathrm{~cm}$.

Stabilitas busa (Awang, Ahmad, dan Ghazali. 2001) dengan cara $200 \mathrm{ml}$ larutan sabun $(0,1 \%$ DHSA) dituang dalam gelas ukur $500 \mathrm{ml}$. Busa dikocok 30 kali. Volume busa kemudian diukur setelah 30 detik dan setelah 5,5 menit. Stabilitas busa dinyatakan sebagai rasio dari volume busa saat menit 5,5 dengan saat 30 detik (V5/V0)

Uji iritasi (Untari dan Robiyanto, 2018) dilakukan terhadap kulit partisipan dilakukan dengan cara uji tempel terbuka (patch test). Uji tempel terbuka dilakukan dengan mengoleskan sabun pada lengan bawah bagian dalam yang dibuat pada lokasi lekatan dengan luas tertentu $\left(2,5 \times 2,5 \mathrm{~cm}^{2}\right)$, dibiarkan terbuka dan diamati apa yang terjadi. Uji ini dilakukan sebanyak 2 kali sehari (pagi dan sore hari) selama 3 hari berturut-turut. Reaksi iritasi positif ditandai oleh adanya kemerahan, gatal-.gatal, atau bengkak pada kulit lengan bawah bagian dalam yang diberi perlakuan.

Uji sensoris yang terdiri dari warna, dan transparansi (Setyaningsih, Apriyantono, dan Sari, 2010).

\section{Hasil dan Pembahasan}

\subsection{Sifat Fisik}

Uji fisik yang dilakukan pada sabun transparan dengan tambahan perlakuan mikropartikel dari ekstrak gambir adalah kekerasan, stabilitas busa dan uji iritasi. Hasil dari pengujian ini ditampilkan pada Tabel 1 berikut.

Tabel 1

Nilai Rata-rata Kekerasan, Stabilitas Busa dan Uji Iritasi Pada Sabun Transparan dengan Penambahan Mikropartikel Ekstrak Gambir

\begin{tabular}{|c|c|c|c|}
\hline $\begin{array}{l}\text { Perlakuan } \\
\text { Ekstrak } \\
\text { Gambir }\end{array}$ & Kekerasan $\left(\mathrm{kg} / \mathrm{cm}^{2}\right)$ & $\begin{array}{l}\text { Stabilitas } \\
\text { Busa }(\%)\end{array}$ & $\begin{array}{l}\text { Uji } \\
\text { Iritasi }\end{array}$ \\
\hline$A=3 \%$ & $17,53 \pm 1,99 \mathrm{~b}$ & $84,18 \pm 0,08^{a}$ & 0 \\
\hline$B=4 \%$ & $16,89 \pm 0,78 \mathrm{ab}$ & $84,48 \pm 0,21^{a}$ & 0 \\
\hline$C=5 \%$ & $16,81 \pm 0,08 \mathrm{ab}$ & $85,22 \pm 0,16^{b}$ & 0 \\
\hline $\mathrm{D}=6 \%$ & $16,59 \pm 1,19 a b$ & $87,12 \pm 0,30^{c}$ & 0 \\
\hline$E=7 \%$ & $15,10 \pm 1,94 \mathrm{ab}$ & $87,38 \pm 0,36^{c}$ & 0 \\
\hline $\mathrm{F}=8 \%$ & $14,44 \pm 0,47 \mathrm{ab}$ & $91,64 \pm 0,05^{d}$ & 0 \\
\hline $\mathrm{G}=9 \%$ & $14,34 \pm 2,21 \mathrm{ab}$ & $91,65 \pm 0,16^{d}$ & 0 \\
\hline $\mathrm{H}=10 \%$ & $13,59 \pm 1,23$ & $95,88 \pm 0,49$ e & 0 \\
\hline
\end{tabular}



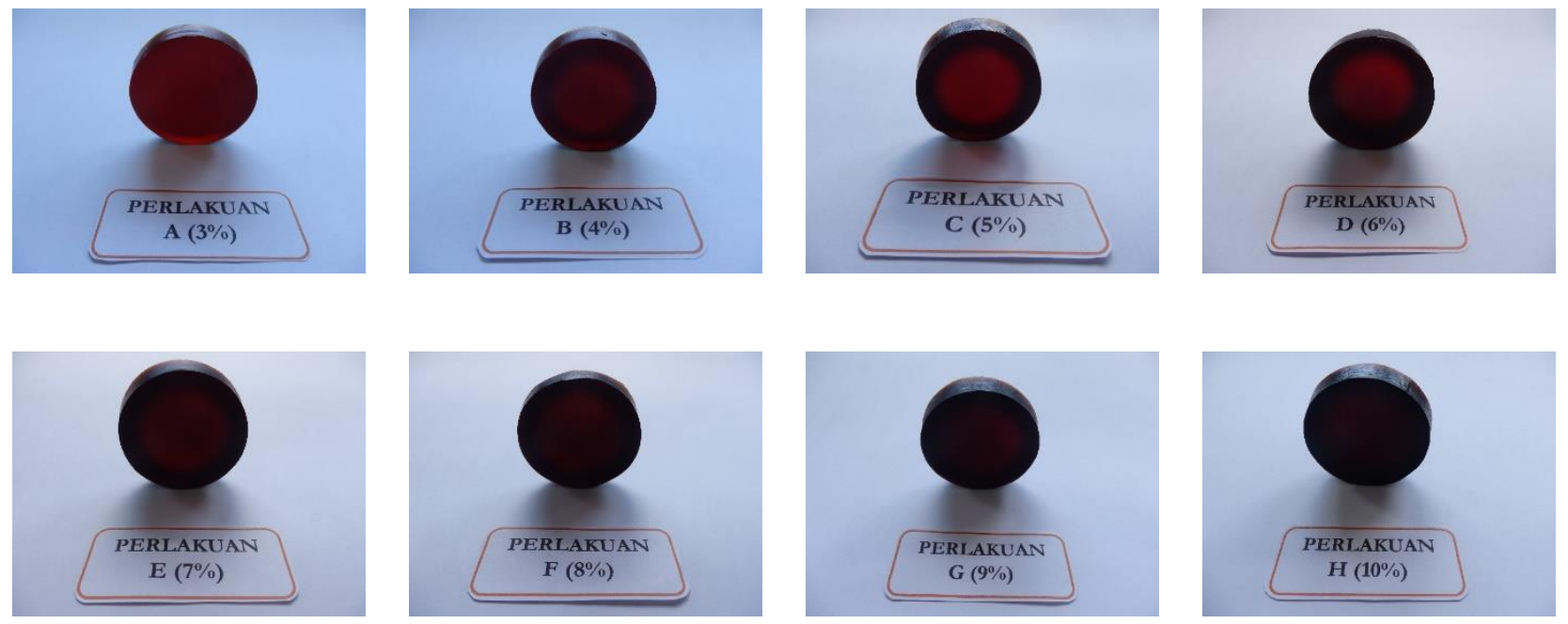

Gambar 1. Sabun Transparan dengan Penambahan Mikropartikel Gambir

\subsubsection{Kekerasan}

Pengujian tingkat kekerasan ditujukan untuk mengetahui efisiensi sabun ketika digunakan. Sabun yang lunak lebih cepat habis dibanding sabun yang keras sewaktu digunakan. Kekerasan sangat dipengaruhi oleh jumlah, jenis asam lemak, kandungan air dan zat menguap yang terkandung dalam sabun. Sabun yang dibuat dari asam lemak dengan bobot molekul kecil seperti asam laurat lebih lunak dari pada sabun yang dibuat dari asam lemak yang bobot molekul lebih besar seperti asam stearat. Sabun yang mengandung kadar air dan zat menguap yang tinggi lebih lunak dibanding sabun yang mengandung kadar air dan zat menguap yang rendah. Uji kekerasan sabun transparan dilakukan dengan menggunakan force gauge.

Hasil analisis sidik ragam dan dilanjutkan dengan uji DNMRT pada taraf nyata $5 \%$ menunjukkan bahwa perbedaan penambahan ekstrak gambir berbentuk mikropartikel berbeda nyata terhadap kekerasan sabun transparan. Gambar 1 menunjukkan sabun yang akan diamati dalam pengujian. Kekerasan sabun transparan yang diperoleh berkisar 13,59 kg/cm² $-17,53 \mathrm{~kg} / \mathrm{cm}^{2}$. Nilai kekerasan sabun transparan tertinggi diperoleh pada penambahan mikropartikel ekstrak gambir 3\% dan nilai kekerasan sabun terendah diperoleh pada penambahan $10 \%$. Nilai kekerasan sabun transparan yang diperoleh dari penelitian ini lebih tinggi dari sabun yang terbuat dari campuran minyak kelapa sawit, minyak kelapa dan minyak zaitun, yaitu maksimal $13 \mathrm{~kg} / \mathrm{cm}^{2}$ (Dunn, 2008).

Seperti yang ditampilkan pada Tabel 1 , semakin banyak penambahan mikropartikel ekstrak gambir maka kekerasan sabun semakin rendah. Perbedaan tingkat kekerasan sabun dipengaruhi oleh kadar air dan kadar zat menguap bahan yang terkandung pada ekstrak gambir. Gambir yang diekstrak dengan etanol 96\% masih mengandung air sebanyak 4\% yang tidak bisa diuapkan pada suhu rotary vacuum evaporator $50^{\circ} \mathrm{C}$. Kandungan air yang terdapat pada mikropartikel ekstrak gambir akan mempengaruhi kandungan air sabun transparan.

Sabun transparan ekstrak pepaya komersial mempunyai tingkat kekerasan sebesar 12,75 $\mathrm{kg} / \mathrm{cm}^{2}$. Jika dibandingkan dengan sabun transparan komersial, sabun transparan hasil penelitian lebih keras karena melalui proses aging selama 3 minggu. Proses aging dimaksudkan selain untuk menyempurnakan reaksi penyabunan juga bisa mengurangi kandungan air pada sabun.

\subsubsection{Stabilitas Busa}

Busa merupakan dispersi gas dalam cairan yang distabilkan oleh suatu zat pembusa, merupakan struktur yang relatif stabil dan terdiri dari kantongkantong udara yang terbungkus dalam lapisan tipis (Widiyanti, 2009).

Berdasarkan analisis sidik ragam yang dilanjutkan dengan uji DNMRT pada taraf nyata 5\% didapatkan bahwa level penambahan mikropartikel gambir berpengaruh nyata terhadap stabilitas busa sabun transparan. Stabilitas busa sabun transparan yang diperoleh berkisar antara 84,18\% - 95,88\%. Nilai stabilitas busa sabun transparan paling tinggi diperoleh pada level penambahan mikropartikel $10 \%$ gambir dan terendah pada level penambahan $3 \%$.

Stabilitas busa semakin meningkat seiring dengan penambahan mikropartikel gambir seperti terlihat pada Tabel 1. Hal ini terkait dengan kandungan saponin pada ekstrak gambir. Saponin memiliki struktur kombinasi polar dan non-polar sehingga memiliki karakteristik seperti sabun yang mudah larut dalam air dan menimbulkan busa ketika diaduk (Vincken, Heng, Groot, dan Gruppen, 2007; Suharto, Edy, dan Dumanauw, 2012). Hasil analisis kualitatif menujukkan bahwa gambir mengandung 
quinon, terpenoid, alkaloid, tannin, flavonoid dan saponin (Ferdinal, Sulistyo dan Nazir, 2013).

\subsubsection{Uji Iritasi}

Evaluasi uji iritasi dilakukan untuk melihat reaksi sabun terhadap kulit. Hasil analisis iritasi pada Tabel 1 hasil pengujian menunjukkan bahwa untuk setiap perlakuan 3\% sampai 10\% tidak terjadi iritasi pada kulit. Iritasi pada kulit dapat terjadi karena $\mathrm{pH}$ yang terlalu tinggi atau terlalu rendah, penambahan etanol yang terlalu banyak serta jumlah alkali bebas yang tinggi. Dalam penelitian ini, $\mathrm{pH}$ dan asam lemak bebas sabun yang dihasilkan telah memenuhi standar mutu SNI 3532:2016 (BSN, 2016).

\subsection{Analisis Sensori}

Hasil analisis sensori sabun transparan ekstrak gambir dapat dilihat pada Tabel 2 .

Tabel 2

Nilai Rata-rata Kesukaan Warna dan Transparansi pada Sabun transparan mikropartikel ekstrak gambir

\begin{tabular}{ccc}
\hline $\begin{array}{c}\text { Perlakuan } \\
\text { Ekstrak Gambir }\end{array}$ & \multicolumn{1}{c}{ Warna } & Transparansi \\
\hline $3 \%$ & $4,70 \pm 0,47 \mathrm{~d}$ & $4,60 \pm 0,60^{\mathrm{d}}$ \\
$4 \%$ & $4,15 \pm 0,67 \mathrm{c}$ & $4,00 \pm 0,62^{\mathrm{c}}$ \\
$5 \%$ & $4,30 \pm 0,47 \mathrm{~cd}$ & $4,20 \pm 0,56^{\mathrm{cd}}$ \\
$6 \%$ & $3,65 \pm 0,67 \mathrm{~b}$ & $3,25 \pm 0,64 \mathrm{~b}$ \\
$7 \%$ & $3,50 \pm 0,95 \mathrm{~b}$ & $3,10 \pm 0,79 \mathrm{~b}$ \\
$8 \%$ & $3,35 \pm 0,67 \mathrm{~b}$ & $2,90 \pm 0,64 \mathrm{~b}$ \\
$9 \%$ & $3,45 \pm 0,76 \mathrm{~b}$ & $3,20 \pm 0,62^{\mathrm{b}}$ \\
$10 \%$ & $2,60 \pm 0,82 \mathrm{a}$ & $2,30 \pm 0,80 \mathrm{a}$ \\
\hline
\end{tabular}

Warna adalah salah satu parameter mutu yang sangat mempengaruhi keputusan konsumen dalam membeli suatu produk. Analisis sidik ragam dan uji DNMRT pada taraf nyata 5\% menunjukkan bahwa perbedaan penambahan mikropartikel ekstrak gambir nyata terhadap tingkat kesukaan warna sabun transparan. Tingkat kesukaan terhadap warna sabun transparan yang diperoleh berkisar 2,60 (biasa)- 4,7 (sangat suka). Tingkat kesukaan tertinggi panelis terhadap warna sabun transparan diperoleh pada penambahan 3\% mikropartikel ekstrak gambir sedangkan tingkat kesukaan panelis terendah adalah pada penambahan $10 \%$.

Tingkat kesukaan panelis terhadap transparansi sabun semakin menurun seiring penambahan mikropartikel gambir. Penambahan mikropartikel ekstrak gambir menyebabkan sabun transparan akan berwarna merah kecoklatan dan semakin gelap. Panelis lebih menyukai sabun transparan yang berwarna merah kecoklatan dan lebih terang dibanding warna sabun transparan berwarna merah kecoklatan gelap. Warna merah kecoklatan pada sabun disebabkan karena adanya asam catechu tannat. Menurut Nazir (2000), gambir mengandung sejumlah besar asam catechu tannat (20\% - 55\%) berupa serbuk berwarna coklat kemerah-merahan dan sejumlah kecil (2\% - 4\%) quersetin yang memberikan warna kuning pada gambir. Diagram laba-laba analisis sensoris dapat dilihat pada Gambar 2.

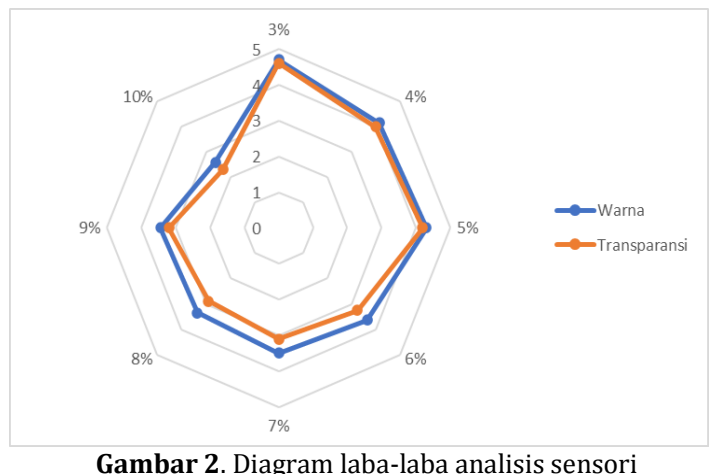

\subsection{Pengamatan Ukuran dan Morfologi Partikel dengan Scanning Electron Microscope (SEM)}

\subsubsection{Pengamatan SEM pada Ekstrak Gambir}

SEM merupakan alat yang dapat menganalisis bentuk dan ukuran sampel. Hasil pengukuran menggunakan SEM dengan perbesaran 200x terlihat bahwa ukuran partikel berkisar antara 12,1 - 22,8 $\mu \mathrm{m}$. Morfologi ekstrak gambir yang diamati memiliki sudut-sudut runcing yang menyerupai jarum. Hal ini juga ditemukan oleh Bakhtiar, Gaesari, dan Zaini (2015) tentang ekstrak katekin dari gambir yang berbentuk seperti jarum pada pengamatan mikroskopik menggunakan SEM (Gambar 3).

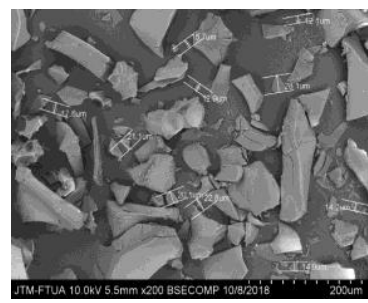

a

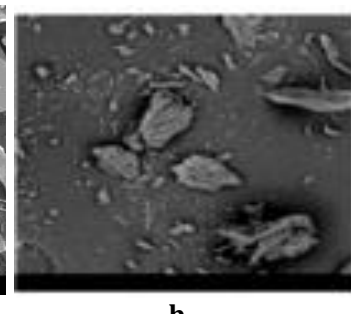

b
Gambar 3. Morfologi dan Ukuran Partikel Ekstrak Gambir a = hasil penelitian dengan perbesaran $200 \mathrm{x}$; b= hasil penelitian Bakhtiar, et al. (2015) dengan perbesaran $1000 \mathrm{x}$

\subsubsection{Pengamatan SEM pada Sabun Transparan}

Hasil pengamatan sabun transparan ekstrak gambir dengan menggunakan SEM dapat dilihat pada Gambar 4. Pada Gambar 4a terlihat bahwa pada penambahan ekstrak gambir $3 \%$, partikel ekstrak gambir menyebar secara merata dalam sistem sabun. Semakin banyak penambahan ekstrak gambir seperti yang terlihat pada gambar $4 \mathrm{~b}$ (penambahan ekstrak gambir 5\%) dan pada Gambar 4c (penambahan ekstrak gambir 10\%) terlihat partikel ekstrak gambir cenderung semakin bergerombol dan beraglomerasi membentuk partikel yang lebih besar di dalam sistem sabun. 


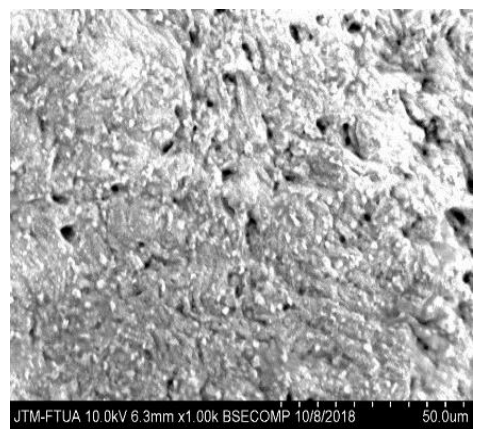

a

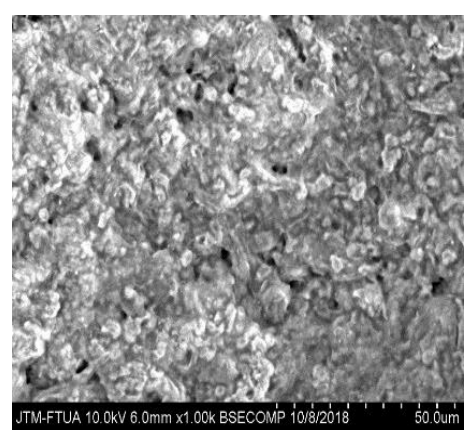

$\mathrm{b}$

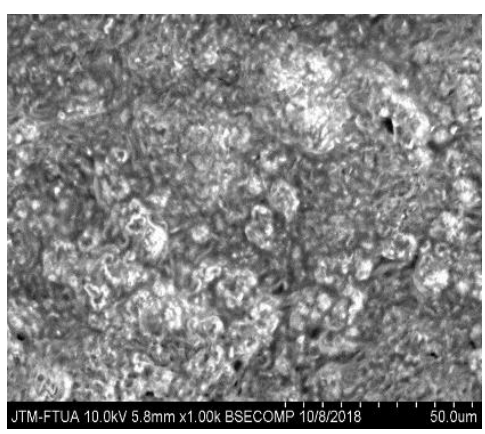

c

Gambar 4. Morfologi Sabun Transparan dengan penambahan ekstrak gambir a (3\%), b (5\%), c (10\%) dengan perbesaran 1000x

\subsection{Rekapitulasi Hasil Pengamatan}

Penambahan mikropartikel ekstrak gambir terbaik berdasarkan hasil pengamatan terhadap sifat fisik dan sifat sensori sabun transparan adalah penambahan 3\%. Penambahan ekstrak gambir yang melebihi $3 \%$ akan menurunkan nilai kesukaan panelis terhadap sifat sensori sabun transparan, terutama pada warna dan transparansi sabun.

Selain itu penambahan ekstrak gambir yang semakin tinggi akan mengurangi tingkat kekerasan sabun transparan. Sabun yang tingkat kekerasan rendah akan mudah habis sehingga kurang disukai oleh konsumen. Rekapitulasi karakteristik sabun transparan dengan penambahan ekstrak mikropartikel gambir dapat dilihat pada Tabel 3.

Tabel 3

Rekapitulasi karakteristik fisik dan sensori sabun transparan dengan penambahan 3\% ekstrak mikropartikel gambir

\begin{tabular}{ll}
\multicolumn{2}{c}{ Pengamatan } \\
\hline Kekerasan $\left(\mathrm{kg} / \mathrm{cm}^{2}\right)$ & \multicolumn{1}{c}{ Nilai } \\
Stabilitas Busa $(\%)$ & $84,18 \pm 0,08$ \\
Uji Iritasi & 0 \\
Warna & $4,70 \pm 0,47$ \\
Transparansi & $4,60 \pm 0,60$ \\
\hline
\end{tabular}

\section{Kesimpulan}

Hasil pengukuran ekstrak gambir menggunakan SEM dengan perbesaran 200x adalah berkisar 12,122,8 $\mu \mathrm{m}$. Penambahan mikropartikel ekstrak gambir pada pembuatan sabun transparan berbahan minyak sawit menghasilkan beberapa perbedaan secara fisik dan karakteristik sensori. Panelis lebih menyukai warna dan transparansi sampel sabun dengan penambahan ekstrak gambir sebesar 3\%. Uji sifat fisik dari sabun tersebut menunjukkan nilai kekerasan $17,53 \mathrm{~kg} / \mathrm{cm}^{2}$, stabilitas busa $84,18 \%$, nol untuk uji iritasi.

\section{Ucapan Terima Kasih}

Ucapan terima kasih disampaikan kepada Dekan Fakultas Teknologi Pertanian Universitas Andalas yang telah memberikan hibah penelitian DIPA 2018 kepada tim penulis.

\section{Daftar Pustaka}

Ahmad, N., Hasan Z. A. A ., Muhammad H., Bilal S.H., Yusof N.Z., \& Idris Z. (2018). Determination of total phenol, flavonoid, antioxidant activity of oil palm leaves extracts and their aplication in transparent soap. Journal of Palm Research, 30(2), 315-325.

Aulia, F. (2013). Studi penyediaan nanokristal selulosa dari tandan kosong sawit (TKS). Skripsi. Universitas Sumatera Utara, Medan.

Awang, R., Ahmad, S., \& Ghazali, R. (2001). Properties of sodium soap derived from palmbased dihydroxystearic acid. Journal of Oil Palm Research, 13(2), 33-38.

Bakhtiar, A., Gaesari, S. R., \& Zaini, E. (2015). Pembentukan kokristal katekin dengan nikotinamida. Jurnal Farmasi Sains dan Terapan, 2(2), 28-32.

BSN. (2016). SNI 3532:2016 Syarat Mutu Sabun Mandi. Jakarta.

Dunn, K. M. (2008). The "water discount". The Journal of The Handcrafted Soapmakers Guild. 2008 (2), 1-5.

Ferdinal, N., Sulistyo, J., \& Nazir, N. (2013). Sintesis enzimatis flavonoid-glikosida dari gambir (Uncaria gambir) menggunakan enzim CGTase dari Bacillus licheniformis. Prosiding Semirata FMIPA Universitas Lampung, 185191.

Food \& Drug Administration. (2016). FDA issues final rule on safety and effectiveness of antibacterial soaps; Rule removes triclosan and triclocarban from over-the-counter antibacterial hand and body washes. Diakses tanggal 19 Juli 2019 dari https://www.fda.gov/news-events/pressannouncements/fda-issues-final-rule-safety- 
and-effectiveness-antibacterial-soaps.

Hambali, E. (2005). Gaya Membuat Sabun Transparan Untuk Gift dan Kecantikan. Jakarta: Penebar Swadaya.

Inomata S. (1999). Antiaging agent. EP0919223A1. European Patent Office.

Nazir, N. (2000). Gambir Budidaya, Pengolahan, dan Prospek Diversifikasinya. Padang: Yayasan Hutanku.

Neswati, N., Ismanto, S. D., \& Derosya, V. (2019). Analisis kimia dan sifat antibakteri sabun transparan berbasis minyak kelapa sawit dengan penambahan ekstrak mikropartikel gambir. Jurnal Agroindustri Halal, 5(2), 171179.

Retnowati, D. S., Kumoro, A. C., Ratnawati, \& Budiyati, C. S. (2013). Pembuatan dan karakterisasi sabun susu dengan proses dingin. Jurnal Rekayasa Proses, 7(2), 46-51.

Setyaningsih, D., Apriyantono, A., \& Sari, M. P. (2010). Analisis Sensori untuk Industri Pangan dan Agro. Bogor: IPB Press.

Setyowati, H. (2017). Gambir (Uncaria gambir Roxb) as natural cosmeceutical agent. Cdk-250, 44(3), 222-224.

Sidqi, T. (2011). Pembuatan dan karakterisasi nanopartikel ekstrak temulawak dengan metode ultrasonikasi. Skripsi, Institut Pertanian Bogor, Bogor.

Suharto, M. A. P., Edy, H. J., \& Dumanauw, J. M. (2012). Isolasi dan identifikasi senyawa saponin dari ekstrak metanol batang pisang ambon (Musa paradisiaca var. sapientum L.). Pharmacon, 1(2), 1-7.

Sumosa, N. S., Efrizal, \& Rahayu, R. (2014). Pengaruh Gambir (Uncaria gambir R.) terhadap penyembuhan luka bakar pada mencit putih (Mus musculus L.) jantan. J Biologi Universitas Andalas, 3(4), 283-288.

Untari, E. K. \& Robiyanto. (2018). Uji Fisikokimia dan Uji Iritasi Sabun Antiseptik Kulit Daun Aloe vera (L.) Burm. F. Jurnal Jamu Indonesia, 3(2), 55-61.

Vincken, J. P, Heng, L., Groot, A., \& Gruppen, H. (2007). Saponins, classification and occurrence in the plant kingdom. Phytochemistry, 68, 275297.

Warnida, H., Masliyana, A., \& Sapri. (2016). Fromulasi ekstrak etanol gambir (Uncaria gambir Roxb) dalam bedak anti jerawat. Jurnal Ilmiah Manuntung, 2(1), 99-106.

Widiyanti, Y. (2009). Kajian pengaruh jenis minyak terhadap mutu sabun transparan. Skripsi, Institut Pertanian Bogor, Bogor 